\title{
Lactation and cancer risk: is there a relation specific to breast cancer?
}

\author{
GUNNAR KVÅLE ${ }^{1}$ AND IVAR HEUCH ${ }^{2}$ \\ From the Institute of Hygiene and Social Medicine, ${ }^{1}$ and Department of Mathematics, ${ }^{2}$ University of Bergen, \\ Norway
}

SUMMARY Relations between previous lactation experience and risks of cancer of the breast and other sites were investigated after follow-up of 50274 parous women from 1961 through 1980. Among women with complete information on lactation, 5102 developed cancer and, of these, 1136 were diagnosed with breast cancer. Analyses of associations with mean duration of lactation per birth and duration for each of the three first births suggested a nonlinear relation to breast cancer. The highest risk was observed for those with intermediate duration of breast feeding, whereas lower risks were found among those with very short or very long duration. For all nongenital cancers combined, decreased risks were observed among those with the longest duration of breast feeding. However, among cancers of specific sites, a significant inverse association was found for pancreatic cancer only. The overall impression given by our data is that breast feeding is not strongly related to risks of breast cancer or any other common cancer.

It has not yet been settled whether any relation exists between lactation and cancer of the breast and genital organs, and the potential effects of lactation on the occurrence of other cancers have scarcely been studied. Two recent reports ${ }^{12}$ have suggested a possible protective effect of prolonged breast feeding in premenopausal women. Results from other investigations, mostly case-control studies, have been equivocal. ${ }^{13}$ However, in a majority of these studies the analyses were based on a rather crude classification of breast feeding experience, which may conceal possible relations, especially if the association with breast cancer is nonlinear.

We here present results from a prospective study of 50274 parous women who, through personal interviews, provided a detailed lactation history as well as information on other reproductive variables. By our follow-up design with use of national cancer registry data, we are able to study effects of lactation on the occurrence of both breast cancer and cancers of other sites. We also avoid problems such as selection and recall bias which may distort results from casecontrol studies. For breast cancer we have previously, from the same cohort, reported a strong inverse association with parity ${ }^{4}$ and more complex relations with ages at first and last birth. ${ }^{5}$

\section{Materials and methods}

In 1956-59, all women aged 20-69 years by 1 January
1956 in four counties in Norway were invited to attend a screening programme for early diagnosis of breast cancer. Each woman was interviewed according to a standard questionnaire and had a clinical breast examination carried out by a physician. Demographic data and information on occupation were retrieved in advance from the local office for population censuses in each municipality. Married housewives were assigned to the occupational class of their husbands. The questionnaire elicited information on different reproductive variables: age at menarche and menopause, number of full-term deliveries, age at first and last birth, number of abortions, and duration of lactation. Lactation experience for each of the three first births as well as total duration of breast feeding for all births were recorded. Furthermore, a history of breast disease or diseases of the genital organs was registered.

In the county of Nord-Trøndelag, three screening examinations were organised, in Aust-Agder two, and in Vest-Agder and Vestfold one examination. The effect of screening has been discussed in a previous report. ${ }^{6}$ In Vest-Agder, the attendance was rather low $(51.7 \%)$, and the present study is confined to residents of the three other counties aged 27-69 years by 1 January 1956, a total of 92573 women. On the basis of name, municipality of residence, and date of birth, the official personal registration number was retrieved for $\mathbf{8 5 0 6 3}$ women who were still alive at the start of follow-up on 1 January 1961. Of these, 63090 had 
attended the screening programme and were interviewed during the years $1956-59$, corresponding to an overall response rate of $74.2 \%$. For the present analyses 11500 nulliparous women and 1316 respondents with missing information on number of births were excluded. Of the remaining 50274 respondents, 1667 women did not provide a complete history of lactation for all children. Among the 48607 women with known parity and total duration of lactation, 5102 developed cancer during the period of follow-up, 1961-80. Of these, 1136 were diagnosed with breast cancer.

The official registration number served as a unique identification of the record for each woman and was used to link follow-up information to our files. Thus, data on cancer cases, obtained from the Cancer Registry of Norway, and complete information concerning emigrations and deaths, from the Central Bureau of Statistics, could be added to the records with information on reproductive variables. Dates of diagnosis and sites of primary tumour were thoroughly checked by the Cancer Registry, and these variables as well as the histological subtype recorded were not revised for this study. The Cancer Registry covers the whole population of Norway, and the registration is practically complete for all sites except non-melanoma skin cancers, leukaemias, and multiple myelomas. ${ }^{7}$ Cancer cases diagnosed at screening in 1956-59 as well as respondents reporting a history of cancer were not included as cases in the study.

The analyses of incidence of breast cancer were adjusted for age at start of follow-up (with five-year age groups) and urban/rural place of residence, and in special cases other demographic and reproductive variables. The adjustment was made by forming a stratum for each combination of covariables.

After appropriate transformation and grouping of the data, ${ }^{8}$ stratified logistic regression analyses were carried out according to the procedure described by Thomas and Gart. ${ }^{9}$ The model assumes that the logit of the probability of getting breast cancer can be expressed as a linear function of a score depending on duration of lactation. For these analyses the respondents were grouped according to duration of breast feeding in months. Thus, categories used for mean duration of lactation per birth were no lactation, durations of $0.1-2.0$ months, $2.1-4.0$ months, 4.1-6.0 months, $6.1-8.0$ months, $8.1-10.0$ months, $10.1-12.0$ months, and more than 12 months. These categories were assigned scores $0,1,2,3,4,5,6$, and 7 , respectively. Duration of lactation for the first, second, and third child and total duration of breast feeding were categorised in a similar way. Odds ratios between adjacent groups could then be estimated from the logistic regression analyses. A test for departure from a linear trend allowed assessment of the appropriateness of the model.

Of the 50274 women followed, 10646 died and 100 emigrated in the period 1961-80. In the estimation procedure, a crude correction for censoring was introduced by decreasing the initial number at risk by half the number of deaths and emigrations occurring among those who did not develop the kind of cancer under study. The analyses also included a test for interaction between the study variable and the separate variables defining strata. The expected numbers of cases in the various categories under the hypothesis of no association were derived in analyses adjusted for times until censoring. ${ }^{10}$ These analyses also produced two-tailed p-values for linear trend.

\section{Results}

Of the 50274 parous women, $8.2 \%$ reported no lactation, and for $3.3 \%$ the total duration of breast feeding was unknown (table 1). Mean duration of lactation per birth differed to some extent between demographic and reproductive categories. A long duration was more common in the older birth-cohorts, in rural areas, and in the counties of Nord-Trøndelag and Aust-Agder as compared with Vestfold. Among the different occupations a long duration of breast feeding was especially common for women married to farmers or engaged in farm work themselves, whereas short duration was most common in the group "fishing, ship's officers, and crew". A high proportion $(21.9 \%)$ of the never-married parous women reported no lactation. Both total parity and age at first birth showed strong associations with nursing habits. The proportion of women reporting no lactation at all fell from $19.3 \%$ among uniparous to $2.6 \%$ for women with five or more births. This proportion also increased with increasing age at first birth, from $4.9 \%$ for respondents with first birth before the age of 20 to $18.5 \%$ for those with first birth at age 35 or later. Although those with late menopause tended to report somewhat longer duration of lactation, neither age at menopause nor age at menarche was strongly related to duration of nursing.

We observed no significant trends in risk according to mean duration of lactation for cancer of the breast and genital organs (table 2). For breast cancer both women with short and long duration of nursing had lower risk than those with intermediate mean duration. Such nonlinear associations still obtained in analyses with additional adjustment for occupation, age at menarche or menopause or age at first birth. Similar tendencies were noted in separate analyses of associations with duration of breast feeding for each of the first three births (figure). For the first and the second child, women reporting no lactation or a very short duration had lower risk than those with 
Table 1 Distribution of mean duration of lactation per birth by demographic and reproductive variables, among parous women, prospective study, Norway, 1961-80.

\begin{tabular}{|c|c|c|c|c|c|c|c|c|c|c|}
\hline & \multirow[t]{2}{*}{ Respondents } & \multicolumn{9}{|c|}{ Percentage respondents by mean duration of lactation (months) } \\
\hline & & $\begin{array}{l}\text { No } \\
\text { lactation }\end{array}$ & $\begin{array}{r}0.1 \\
-2.0\end{array}$ & $\begin{array}{r}2 \cdot 1 \\
-4 \cdot 0\end{array}$ & $\begin{array}{r}4 \cdot 1 \\
-6.0\end{array}$ & $\begin{array}{r}6 \cdot 1 \\
-8 \cdot 0\end{array}$ & $\begin{array}{r}8 \cdot 1 \\
-10 \cdot 0\end{array}$ & $\begin{array}{r}10 \cdot 1 \\
-12.0\end{array}$ & $>12$ & Unknown \\
\hline Total series & 50274 & $8 \cdot 2$ & 14.5 & $14 \cdot 4$ & $14 \cdot 4$ & $12 \cdot 9$ & $21 \cdot 4$ & $9 \cdot 0$ & 1.9 & $3 \cdot 3$ \\
\hline \multicolumn{11}{|l|}{ Year of birth: } \\
\hline $1886-1890$ & 1765 & $6 \cdot 3$ & $5 \cdot 4$ & $7 \cdot 3$ & $10 \cdot 2$ & $10 \cdot 2$ & $24 \cdot 9$ & $22 \cdot 5$ & $4 \cdot 1$ & $9 \cdot 0$ \\
\hline $1891-1900$ & 8167 & $6 \cdot 1$ & 7.0 & 8.9 & $12 \cdot 2$ & $12 \cdot 6$ & $27 \cdot 0$ & $17 \cdot 0$ & 3.4 & $5 \cdot 7$ \\
\hline $1901-1910$ & 12256 & 7.9 & $10 \cdot 7$ & $12 \cdot 3$ & $14 \cdot 0$ & $14 \cdot 1$ & $25 \cdot 0$ & $10 \cdot 5$ & $2 \cdot 4$ & $3 \cdot 1$ \\
\hline $1911-1920^{*}$ & 16228 & $8 \cdot 2$ & $15 \cdot 8$ & $15 \cdot 8$ & $15 \cdot 8$ & 13.6 & $20 \cdot 6$ & 6.5 & $1 \cdot 3$ & $2 \cdot 5$ \\
\hline $1921-1928^{*}$ & 11858 & $10 \cdot 2$ & $23 \cdot 3$ & $19 \cdot 6$ & $15 \cdot 2$ & $11 \cdot 3$ & $14 \cdot 2$ & $3 \cdot 3$ & 0.8 & $2 \cdot 2$ \\
\hline \multicolumn{11}{|l|}{ Place of residence: } \\
\hline Urban & 9967 & $10 \cdot 8$ & $17 \cdot 8$ & $16 \cdot 5$ & $14 \cdot 4$ & $12 \cdot 0$ & $18 \cdot 6$ & 6.6 & $1 \cdot 7$ & 1.6 \\
\hline Rural & 40307 & $7 \cdot 5$ & $13 \cdot 7$ & 13.9 & $14 \cdot 4$ & $13 \cdot 1$ & $22 \cdot 1$ & $9 \cdot 6$ & 1.9 & 3.7 \\
\hline Nord-Trøndelag & 17617 & $5 \cdot 4$ & 11.8 & $13 \cdot 6$ & $15 \cdot 3$ & $14 \cdot 8$ & 23.9 & $8 \cdot 6$ & $1 \cdot 1$ & $5 \cdot 5$ \\
\hline Aust-Agder & 10442 & $9 \cdot 3$ & $13 \cdot 7$ & $12 \cdot 9$ & $12 \cdot 9$ & $11 \cdot 6$ & $20 \cdot 4$ & $11 \cdot 8$ & $3 \cdot 3$ & $4 \cdot 1$ \\
\hline Vestfold & 22215 & $9 \cdot 8$ & $17 \cdot 0$ & $15 \cdot 9$ & $14 \cdot 4$ & 11.9 & $19 \cdot 8$ & $8 \cdot 1$ & $1 \cdot 8$ & $1 \cdot 2$ \\
\hline \multicolumn{11}{|l|}{ Occupation, own or husband's: } \\
\hline Professional & 6433 & $8 \cdot 4$ & $16 \cdot 0$ & $18 \cdot 3$ & $16 \cdot 9$ & $12 \cdot 7$ & $20 \cdot 3$ & $4 \cdot 6$ & 0.7 & $2 \cdot 0$ \\
\hline Private enterprise & 6949 & $8 \cdot 0$ & $15 \cdot 4$ & $16 \cdot 1$ & $14 \cdot 8$ & $13 \cdot 1$ & $20 \cdot 6$ & $7 \cdot 8$ & 1.9 & $2 \cdot 5$ \\
\hline Fishing, ship's officers, crew & 4684 & $10 \cdot 4$ & $17 \cdot 4$ & 14.9 & $14 \cdot 0$ & $12 \cdot 1$ & $19 \cdot 4$ & $8 \cdot 2$ & $2 \cdot 1$ & $1 \cdot 5$ \\
\hline Farm and forestry work & 12035 & $5 \cdot 4$ & $10 \cdot 0$ & $12 \cdot 1$ & $14 \cdot 4$ & $14 \cdot 3$ & $24 \cdot 0$ & $12 \cdot 2$ & $2 \cdot 1$ & $5 \cdot 6$ \\
\hline Labourers, industry, other & 14422 & $9 \cdot 4$ & $16 \cdot 4$ & $14 \cdot 2$ & $13 \cdot 5$ & $12 \cdot 3$ & $20 \cdot 9$ & 8.9 & $2 \cdot 1$ & $2 \cdot 4$ \\
\hline Unknown & 5751 & $9 \cdot 1$ & $14 \cdot 2$ & $13 \cdot 4$ & $13 \cdot 9$ & $12 \cdot 0$ & 20.8 & $9 \cdot 8$ & $2 \cdot 0$ & $4 \cdot 8$ \\
\hline \multicolumn{11}{|l|}{ Marital status: } \\
\hline Married & 46184 & $8 \cdot 1$ & $14 \cdot 9$ & $14 \cdot 7$ & $14 \cdot 6$ & $13 \cdot 0$ & $21 \cdot 1$ & $8 \cdot 6$ & $1 \cdot 7$ & $3 \cdot 2$ \\
\hline Widowed & 2869 & $6 \cdot 3$ & $9 \cdot 2$ & $11 \cdot 3$ & $12 \cdot 5$ & 11.9 & $25 \cdot 7$ & $14 \cdot 6$ & $3 \cdot 2$ & $5 \cdot 2$ \\
\hline Divorced & 413 & $10 \cdot 2$ & $15 \cdot 3$ & $13 \cdot 3$ & $15 \cdot 7$ & $10 \cdot 7$ & 18.9 & $9 \cdot 7$ & $2 \cdot 7$ & 3.6 \\
\hline Never married & 606 & $21 \cdot 9$ & $10 \cdot 9$ & $9 \cdot 6$ & $9 \cdot 2$ & $9 \cdot 7$ & $19 \cdot 8$ & $10 \cdot 4$ & $4 \cdot 8$ & 3.6 \\
\hline Not specified & 202 & 9.9 & $17 \cdot 8$ & $10 \cdot 9$ & $12 \cdot 9$ & 11.9 & $21 \cdot 3$ & $11 \cdot 4$ & $2 \cdot 0$ & $2 \cdot 0$ \\
\hline \multicolumn{11}{|l|}{ Parity } \\
\hline 1 & 10612 & $19 \cdot 3$ & $17 \cdot 6$ & $14 \cdot 5$ & $8 \cdot 2$ & 7.9 & 20.6 & 7.9 & $2 \cdot 3$ & 1.7 \\
\hline 2 & 16431 & 6.9 & $17 \cdot 6$ & $15 \cdot 2$ & $17 \cdot 5$ & $12 \cdot 4$ & $19 \cdot 5$ & $7 \cdot 4$ & 1.6 & 1.9 \\
\hline 3 & 11094 & $4 \cdot 8$ & $13 \cdot 1$ & $16 \cdot 3$ & 16.4 & $15 \cdot 3$ & $21 \cdot 5$ & 8.4 & 1.8 & $2 \cdot 4$ \\
\hline 4 & 5949 & 3.9 & $10 \cdot 8$ & $13 \cdot 3$ & $15 \cdot 0$ & $16 \cdot 5$ & $24 \cdot 2$ & 10.6 & $2 \cdot 2$ & 3.5 \\
\hline$\geq 5$ & 6188 & $2 \cdot 6$ & $7 \cdot 1$ & $10 \cdot 0$ & $13 \cdot 0$ & $14 \cdot 7$ & 24.9 & 14.9 & 1.6 & $11 \cdot 2$ \\
\hline \multicolumn{11}{|l|}{ Age at first birth (years): } \\
\hline$<20$ & 2406 & $4 \cdot 9$ & $13 \cdot 8$ & $13 \cdot 1$ & $16 \cdot 6$ & $14 \cdot 4$ & 20.9 & $9 \cdot 6$ & $2 \cdot 1$ & $4 \cdot 7$ \\
\hline $20-24$ & 17086 & $5 \cdot 3$ & $13 \cdot 7$ & $13 \cdot 9$ & $15 \cdot 1$ & $13 \cdot 7$ & $22 \cdot 2$ & $10 \cdot 3$ & $2 \cdot 2$ & $3 \cdot 5$ \\
\hline $25-29$ & 17507 & $8 \cdot 0$ & $15 \cdot 3$ & $15 \cdot 2$ & $15 \cdot 0$ & $13 \cdot 4$ & $21 \cdot 1$ & $8 \cdot 2$ & 1.6 & $2 \cdot 4$ \\
\hline $30-34$ & 7733 & 11.5 & $16 \cdot 1$ & $15 \cdot 1$ & 13.5 & 11.6 & $20 \cdot 8$ & $7 \cdot 3$ & 1.7 & $2 \cdot 6$ \\
\hline$\geq 35$ & 3180 & 18.5 & $14 \cdot 6$ & 14.9 & 10.9 & 8.9 & $19 \cdot 3$ & $8 \cdot 1$ & $2 \cdot 2$ & $2 \cdot 6$ \\
\hline Unknown & 2362 & 8.6 & $9 \cdot 7$ & $11 \cdot 7$ & $11 \cdot 4$ & $11 \cdot 0$ & $22 \cdot 7$ & $12 \cdot 1$ & 1.8 & 10.9 \\
\hline
\end{tabular}

*Still in childbearing age at the time of interview

durations from 4 to 10 months. For those with longest duration (more than 10 months) a consistent decrease in risk was observed. The departure from linear trend reached statistical significance for the second child only $(p=0.05)$. We observed no statistically significant difference in the effect of mean duration of lactation according to age at breast cancer diagnosis (table 3).

For cancers of all sites a departure from linear trend was indicated, and women with very long duration tended to have low risk, of both breast cancer and nongential cancers (table 2). A slight negative trend was suggested for cancer of the corpus uteri, with decreasing risk for a longer duration of lactation. For pancreatic cancer we observed a significant inverse association with high risk among women reporting no lactation or only a very short duration (table 4). No significant associations were found for any other common cancer.

Total duration of breast feeding for all children showed significant inverse associations with cancers of the breast and corpus uteri in initial analyses with adjustment for age and place of residence only (table 5). After additional adjustment for parity no consistent relation remained for these cancers, whereas a significant inverse association emerged for 
Table 2 Mean duration of lactation and cancer risk. Observed number of cases $(O)$, observed/expected ratio $(O / E)$, and odds ratio corresponding to an increase in lactation of two months, ${ }^{*}$ for cancers of the breast and genital organs and all other sites, Norway, $1961-80$.

\begin{tabular}{|c|c|c|c|c|c|c|c|c|c|c|c|c|c|}
\hline \multirow[b]{3}{*}{ Cancer Site } & \multirow[b]{3}{*}{ Score } & \multicolumn{8}{|c|}{ Mean duration of lactation per birth (months) } & \multirow{3}{*}{$\begin{array}{l}\text { Total } \\
\text { no. of } \\
\text { cases }\end{array}$} & \multirow{3}{*}{$\begin{array}{l}\text { Odds ratio } \\
\text { (with } 95 \% \text { CI) } \\
\text { per } 2 \text { months }\end{array}$} & \multirow{3}{*}{$\begin{array}{l}p \\
\text { for } \\
\text { linear } \\
\text { trend }\end{array}$} & \multirow{3}{*}{$\begin{array}{l}\text { p for } \\
\text { departure } \\
\text { from linear } \\
\text { trend }\end{array}$} \\
\hline & & $\begin{array}{l}\text { No } \\
\text { lactation }\end{array}$ & $\begin{array}{r}0.1 \\
-2.0\end{array}$ & $\begin{array}{r}2.1 \\
-4.0\end{array}$ & $\begin{array}{r}4.1 \\
-6.0\end{array}$ & $\begin{array}{r}6 \cdot 1 \\
-8.0\end{array}$ & $\begin{array}{r}8.1 \\
-10.0\end{array}$ & $\begin{array}{r}10.1 \\
-12.0\end{array}$ & $>12$ & & & & \\
\hline & & (0) & (1) & (2) & (3) & (4) & (5) & (6) & (7) & & & & \\
\hline All sitest & $\begin{array}{l}O \\
\text { O/E }\end{array}$ & $\begin{array}{l}422 \\
1.00\end{array}$ & $\begin{array}{l}693 \\
1.05\end{array}$ & $\begin{array}{l}671 \\
0.96\end{array}$ & $\begin{array}{l}746 \\
1.02\end{array}$ & $\begin{array}{l}647 \\
0.94\end{array}$ & $\begin{array}{l}1278 \\
1.05\end{array}$ & $\begin{array}{l}546 \\
0.96\end{array}$ & $\begin{array}{l}99 \\
0.85\end{array}$ & 5102 & $1.00(0.98-1.01)$ & 0.50 & 0.06 \\
\hline Breast & $\begin{array}{l}\mathbf{O} \\
\mathbf{O} / \mathbf{E}\end{array}$ & $\begin{array}{l}96 \\
0.92\end{array}$ & $\begin{array}{l}155 \\
0.96\end{array}$ & $\begin{array}{l}152 \\
0.94\end{array}$ & $\stackrel{182}{1 \cdot 12}$ & $\begin{array}{l}140 \\
0.94\end{array}$ & ${ }_{1 \cdot 11}^{287}$ & $\begin{array}{l}108 \\
0.95\end{array}$ & $\begin{array}{l}16 \\
0.66\end{array}$ & 1136 & $1.01(0.98-1.05)$ & 0.49 & $0 \cdot 12$ \\
\hline Cervix uteri & $\begin{array}{l}0 \\
\text { O/E }\end{array}$ & $\begin{array}{l}32 \\
1 \cdot 15\end{array}$ & 64 & $\begin{array}{l}51 \\
0.94\end{array}$ & $\begin{array}{l}47 \\
0.90\end{array}$ & $\begin{array}{l}38 \\
0.82\end{array}$ & $\begin{array}{l}70 \\
0.97\end{array}$ & $\begin{array}{l}28 \\
0.98\end{array}$ & $\begin{array}{l}11 \\
1.91\end{array}$ & 341 & $0.98(0.92-1.04)$ & 0.48 & 0.15 \\
\hline Corpus uteri & $\begin{array}{l}\mathbf{O} \\
\mathbf{O} / \mathbf{E}\end{array}$ & $\begin{array}{l}29 \\
1.08\end{array}$ & ${ }_{1.03}^{46}$ & $\stackrel{51}{1=15}$ & $\begin{array}{l}47 \\
1.07\end{array}$ & $\begin{array}{l}33 \\
0.83\end{array}$ & $\begin{array}{l}65 \\
0.97\end{array}$ & $\begin{array}{l}22 \\
0.82\end{array}$ & $\begin{array}{l}6 \\
1.04\end{array}$ & 299 & $0.96(0.90-1.02)$ & 0.21 & 0.92 \\
\hline Ovary & $\begin{array}{l}\mathbf{O} \\
\mathbf{O} / \mathbf{E}\end{array}$ & $\begin{array}{l}33 \\
1.09\end{array}$ & $\begin{array}{l}53 \\
1 \cdot 17\end{array}$ & $\begin{array}{l}34 \\
0.74\end{array}$ & $\begin{array}{l}49 \\
1.09\end{array}$ & $\begin{array}{l}35 \\
0.84\end{array}$ & $\begin{array}{l}76 \\
1.03\end{array}$ & $\begin{array}{l}32 \\
1.06\end{array}$ & $\begin{array}{l}7 \\
1.03\end{array}$ & 319 & $0.99(0.94-1.06)$ & 0.82 & 0.40 \\
\hline $\begin{array}{l}\text { All sites except } \\
\text { breast \& genital organs }\end{array}$ & $\begin{array}{l}\mathbf{O} \\
\mathbf{O} / \mathbf{E}\end{array}$ & $\begin{array}{l}241 \\
0.99\end{array}$ & $\begin{array}{l}397 \\
1.06\end{array}$ & $\begin{array}{l}400 \\
0.99\end{array}$ & $\begin{array}{l}435 \\
0.98\end{array}$ & $\begin{array}{l}416 \\
0.98\end{array}$ & $\begin{array}{l}813 \\
1.06\end{array}$ & $\begin{array}{l}359 \\
0.94\end{array}$ & $\begin{array}{l}61 \\
0.80\end{array}$ & 3122 & $0.99(0.97-1.02)$ & 0.42 & 0.20 \\
\hline
\end{tabular}

- Odds ratio based on logistic regression analyses, adjusted for age, urban/rural place of residence, and parity. Two-tailed p-values.

t Women with cancers of more than one site counted as single cases. Total number is thus less than sum of individual sites.

Table 3 Mean duration of lactation and breast cancer risk. Observed number of cases, and odds ratio* corresponding to an increase in lactation of two months, by age at diagnosis, Norway, 1961-80.
Table 4 Mean duration of lactation and cancer risk. Observed number of cases, and odds ratio corresponding to an increase in lactation of two months, Norway, 1961-80.*

\begin{tabular}{|c|c|c|c|}
\hline Primary site (ICD-7 no.) & $\begin{array}{c}\text { Total no. } \\
\text { of cases }\end{array}$ & $\begin{array}{l}\text { Odds } \\
\text { ratio }\end{array}$ & $\begin{array}{l}\text { p for } \\
\text { linear } \\
\text { trend }\end{array}$ \\
\hline $\begin{array}{l}\text { All persons with cancer (140-205) } \\
\text { Buccal cavity and pharynx (140-148) } \\
\text { Oesophagus (150) } \\
\text { Stomach (151) } \\
\text { Colon, including rectosigmoid (153) } \\
\text { Rectum, excluding rectosigmoid (154) } \\
\text { Liver and gall ducts (155) } \\
\text { Pancreas (157) } \\
\text { Trachea, bronchus, lung (162-163) } \\
\text { Breast and genital organs (170-179) } \\
\text { Kidney (180) } \\
\text { Bladder (181) } \\
\text { Melanoma skin (190) } \\
\text { Non-melanoma skin (191) } \\
\text { Eye (192) } \\
\text { Nervous system (193) } \\
\text { Thyroid gland (194) } \\
\text { Lymphoma (200-202,205) } \\
\text { Multiple myeloma (203) } \\
\text { Leukaemia (204) }\end{array}$ & $\begin{array}{r}5102 \\
52 \\
21 \\
372 \\
447 \\
197 \\
59 \\
156 \\
105 \\
2130 \\
126 \\
84 \\
127 \\
615 \\
20 \\
63 \\
51 \\
121 \\
82 \\
117\end{array}$ & $\begin{array}{l}1.00 \\
0.87 \\
1.03 \\
1.03 \\
1.02 \\
0.99 \\
1.08 \\
0.91 \\
1.03 \\
1.00 \\
1.07 \\
0.92 \\
1.00 \\
0.97 \\
0.80 \\
0.99 \\
1.03 \\
0.97 \\
0.99 \\
0.94\end{array}$ & $\begin{array}{l}0.50 \\
0.07 \\
0.86 \\
0.40 \\
0.43 \\
0.73 \\
0.30 \\
0.03 \\
0.54 \\
0.87 \\
0.17 \\
0.13 \\
0.92 \\
0.15 \\
0.06 \\
0.87 \\
0.75 \\
0.58 \\
0.82 \\
0.241\end{array}$ \\
\hline
\end{tabular}

- Sites with < 20 cases excluded. Odds ratio per 2 months based on logistic regression analyses, adjusted for age, urban/rural place of residence and parity. Two-tailed p-values.

+ Significant departure from linear trend $(p<0.05)$.

\section{Discussion}

We have reported relations betwen cancer incidence and mean duration of lactation per birth, total 

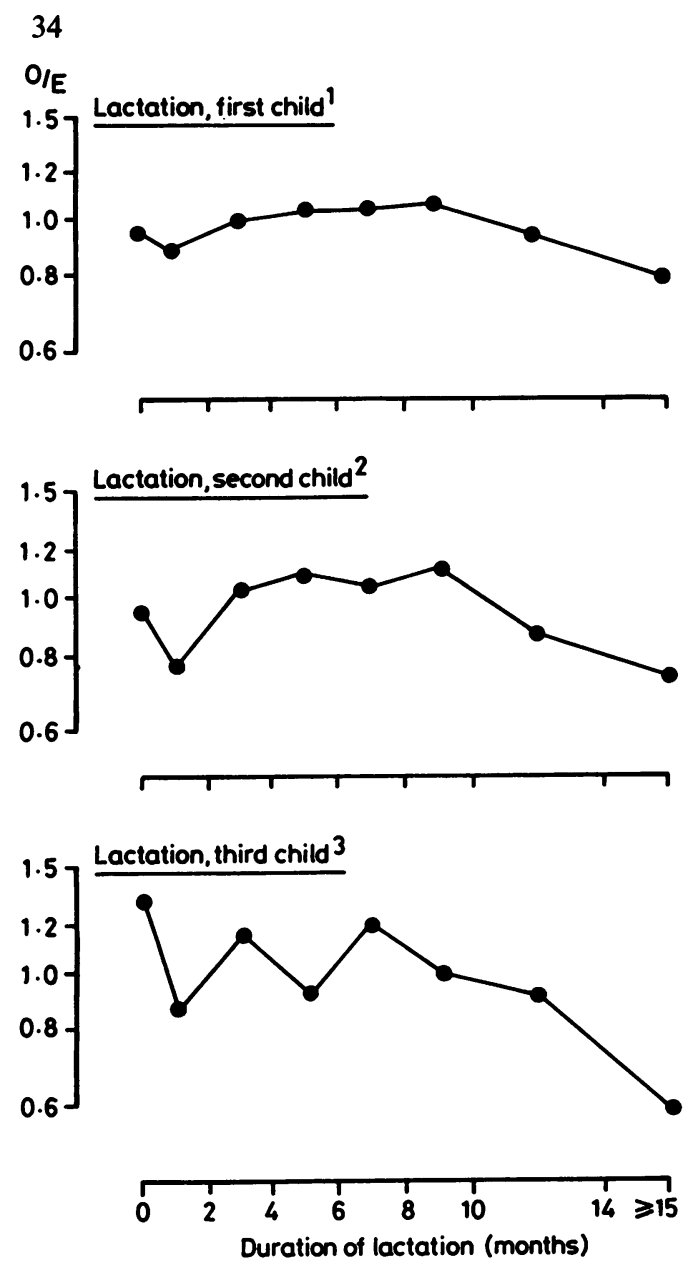

Breast cancer risk and lactation. Observed/expected ratio $(O / E)$ by duration of lactation for the three first births. Adjusted for age at start of follow-up, urban-rural place of residence, and parity.

${ }^{1}$ Analysis of 1143 cases among 49169 women with $\geq 1$ birth

2 Analysis of 837 cases among 38542 women with $\geq 2$ births

3 Analysis of 455 cases among 22321 women with $\geq 3$ births

duration, and duration for each of the three first births. The correlation coefficients between duration of lactation for separate births were of the order of 0.7 . Thus, mean duration per birth should constitute a good summary measure of the breast feeding for any individual child. Our results indicate nonlinear relations with breast cancer for mean duration of lactation as well as duration for each child. In analyses with adjustment for parity, total duration of nursing showed no association with breast cancer.

Despite extensive studies, there is no general agreement about the relation between lactation and
Gunnar Kvåle and Ivar Heuch

breast cancer risk. Though several early reports indicated a possible inverse association, many investigators have found no overall effect after adjustment for parity. ${ }^{3}$ Most previous studies have been of the case-control type, with analyses based on a crude classification of breast feeding experience (mainly ever versus never having breastfed). This may conceal possible relations, ${ }^{1}$ especially if the association with breast cancer risk is nonlinear. Thus, despite an indicated decrease in risk for women reporting very long duration of nursing, our relative risk estimate for ever versus never having breastfed was 1.11 , similar to results for the age group 50 or more in most previous studies. ${ }^{1}$

We found no difference in the effects of lactation according to age at breast cancer diagnosis. Thus, our data do not support results from three case-control studies $^{1211}$ which indicated a protective effect of breast feeding among premenopausal women. However, as in our study, the data for postmenopausal women were consistent with a nonlinear relation, with a low risk for women who never had breastfed as well as for women with a long duration of lactation. In our cohort we could not examine the effect on breast cancer risk in thep very young as only seven cases occurred before the age of 40 .

Explanations of the potential protective effect of long duration of breast feeding have involvec hormonal changes or physical effects on the breast of factors related to nursing. ${ }^{12}$ Hormonal effects of lactation on cancer risk could be expected to affect cancers of breast and corpus uteri in the same direction, whereas direct physical effects should be related to breast cancer only. Thus, the indications of a departure from linear trend observed for breast cancer, but not for cancer of the corpus uteri, might suggest a dual effect of lactation on the risk of breast cancer.

That physical factors may influence breast cancer risk was indicated by the results of Segi et al. ${ }^{12}$ They found that women with a history of hyposecretion of milk from one breast tended to have their tumours on the side that did not lactate sufficiently. Furthermore, in a study in Hong Kong, ${ }^{13}$ postmenopausal women who had habitually breastfed from one breast only, had significantly increased risk of developing cancer in the unsuckled breast. Weaning the child at a time with high milk production will sometimes cause symptoms or physical signs from the breasts. The nonlinear relation for cancer of the breast seen in this study would be expected if such physical factors increased the risk among those with intermediate duration of lactation. Hormonal factors may still contribute to the decreased risk for those with long duration and could affect cancer of the corpus uteri in a similar way. 
Table 5 Total duration of lactation and incidence of selected cancers. Observed number of cases $(O)$, observed/expected ratio $(O / E)$, and odds ratio corresponding to an increase in total lactation of six months, prospective study, Norway, 1961-80.

\begin{tabular}{|c|c|c|c|c|c|c|c|c|c|}
\hline & \multicolumn{3}{|c|}{ Cancer of the breast } & \multicolumn{3}{|c|}{ Cancer of the corpus uteri } & \multicolumn{3}{|c|}{ Pancreatic cancer } \\
\hline & $O$ & $O / E^{*}$ & $O / E t$ & $O$ & $O / E^{*}$ & $O / E \dagger$ & $O$ & $O / E^{*}$ & $O / E \dagger$ \\
\hline Total series & 1102 & 1.00 & $1 \cdot 00$ & 289 & 1.00 & 1.00 & 140 & 1.00 & 1.00 \\
\hline \multicolumn{10}{|l|}{ Lifetime duration of lactation } \\
\hline No lactation & 95 & 1.01 & 0.92 & 28 & $1 \cdot 14$ & 1.05 & 16 & 1.44 & $1 \cdot 52$ \\
\hline 1 - 6 months & 252 & 1.07 & 1.00 & 67 & 1.05 & 0.96 & 25 & 1.03 & 1.09 \\
\hline $7-12$ months & 260 & 1.05 & 1.00 & 74 & $1 \cdot 14$ & 1.07 & 30 & 0.98 & 1.06 \\
\hline $13-18$ months & 180 & 1.02 & 1.05 & 50 & 1.06 & 1.06 & 20 & 0.90 & 0.90 \\
\hline $19-24$ months & 112 & 0.97 & 1.01 & 23 & 0.76 & 0.80 & 16 & 0.99 & 0.94 \\
\hline $25-30$ months & 87 & 0.97 & 1.04 & 20 & 0.84 & 1.02 & 13 & 1.02 & 0.85 \\
\hline $31-36$ months & 56 & 0.82 & 0.92 & 9 & 0.53 & 0.59 & 12 & $1 \cdot 11$ & 1.00 \\
\hline $37-42$ months & 22 & 1.03 & 1.31 & 10 & 1.90 & $2 \cdot 37$ & 2 & 0.59 & 0.61 \\
\hline$\geq 43$ months & 38 & 0.72 & 0.93 & 8 & 0.66 & 0.94 & 6 & 0.67 & 0.73 \\
\hline $\begin{array}{l}\text { Odds ratio \# per } 6 \text { months } \\
\text { (with } 95 \% \text { C.I.) } \\
\text { p for linear trend }\end{array}$ & & $\begin{array}{l}0.96 \\
(0.93-0.99) \\
0.01\end{array}$ & $\begin{array}{l}1.01 \\
(0.97-1.05) \\
0.68\end{array}$ & & $\begin{array}{l}0.94 \\
(0.88-1 \cdot 00) \\
0.05\end{array}$ & $\begin{array}{l}0.99 \\
(0.92-1.07) \\
0.80\end{array}$ & & $\begin{array}{l}0.95 \\
(0.88-1.03) \\
0.22\end{array}$ & $\begin{array}{l}0.89 \\
(0.81-0.98) \\
0.02\end{array}$ \\
\hline
\end{tabular}

- Among parous with 1-5 births, adjusted for age at start of follow-up and urban/rural place of residence

+ Also adjusted for parity

\# Odds ratio based on logistic regression analyses

In our study we had no information on the reason for stopping breast feeding, nor regarding breast symptoms in the weaning period. Thus, we could not re-evaluate the finding of Byers et al, ${ }^{1}$ that those who reported "insufficient milk" as a reason for weaning had a high risk of breast cancer. However, Wynder et $a l,{ }^{14}$ found no association with adequacy of lactation.

Analyses of relations with total duration of breast feeding may assist in discriminating between physical and hormonal effects on breast cancer risk. If hormonal factors were of importance, one would anticipate an inverse association with mean duration of lactation as well as total lifetime duration, provided that the effects from successive pregnancies acted in a cumulative fashion. By contrast, nonlinear associations with mean duration and durations for separate births, due to physical factors, would be concealed in analyses of total duration of lactation.

We found no indication of any inverse association between breast cancer and total duration of lactation in analyses adjusted for parity. This observation, from a large prospective study examining a wide range of durations, should represent a relatively unbiased estimate of the effect of total lifetime duration of lactation on breast cancer risk in women over the age of 40. Our results are in agreement with the finding from the multinational case-control study by MacMahon et al, ${ }^{15}$ who observed that, once parity was allowed for, even women who had lactated for a total of five years or more occurred no less frequently among breast cancer cases than among controls. Taken together these results suggest that hormonal changes during lactation do not markedly influence the risk of breast cancer. Furthermore, as for breast cancer, cancer of the corpus uteri was not related to total lifetime duration of breast feeding in our study.

The risk of cancer of the corpus uteri tended to decrease with increasing mean duration of lactation, but, unlike breast cancer, no lactation or a short duration was not associated with low risk. The association was, however, not statistically significant, and previous studies have shown no definite relation between breast feeding and risk of endometrial cancer. ${ }^{16-18}$ For ovarian cancer we observed no indication of any decreased risk for women with prolonged breast feeding. Although one previous study indicated a protective effect of lactation on ovarian cancer, ${ }^{19}$ three others showed no such relation. ${ }^{20-22}$

Examination of associations with nongenital cancers indicated that the low risk among women with long duration of nursing was not restricted to breast cancer. For pancreatic cancer we observed a significant inverse association, mainly due to high risk in women with mean duration of breast feeding of less than two months. With multiple analyses some spurious significant associations can be expected, and the association with pancreatic cancer may easily represent a chance finding. It is, however, possible that women with short duration of breast feeding have a lifestyle related to high risk of pancreatic cancer, for example, smoke more heavily or have a higher alcohol consumption than those who successfully nurse for prolonged periods. In another Norwegian prospective study, pancreatic cancer was related to high alcohol consumption. ${ }^{23}$ In the present study it may be 
noteworthy that lactation was inversely associated, although not statistically significant, with other cancers where use of alcohol may be of aetiological importance, for example cancers of the buccal cavity and pharynx (table 3 ) and primary liver cancer ( 9 cases only). For lung cancer we found no association with lactation, which indicates that smoking is a less likely confounder.

It is thus possible that the negative trends in risks with increasing mean duration of breast feeding seen for some nongenital cancers can be attributed to confounding. The departure from linear trend, with the highest risk for those with intermediate mean duration of lactation and a consistent decrease in risk for those with long duration, seemed to be specific to breast cancer. Cancer of the corpus uteri was not strongly related to mean duration and, like breast cancer, not related to total lifetime duration of lactation. These findings indicate that a relation with lactation per se may be specific to breast cancer, and overall our results point to physical rather than hormonal explanations.

In rural areas of many developing countries the normal duration of breast feeding is well above one year. ${ }^{24}$ If the protective effects of very long average duration of breast feeding, indicated in our study, prove to be real, breast feeding habits may be among the factors explaining the low risk of breast cancer in such countries. Thus, in a case-control study from South Africa, a decreased breast cancer risk was observed among black women with average duration of breast feeding per birth of 24 months or more, both in pre- and postmenopausal women. ${ }^{11}$ However, in most other studies, including our own, the observed effects of breast feeding were not very strong, and a discussion of this kind may still be premature.

The potential nonlinear relation observed by us should be looked for in other studies. At present, however, it may be difficult in industrialised countries to examine effects of lactation adequately, especially with regard to prolonged breast feeding. This is partly because of the generally short duration of breast feeding in these populations. Another problem is that women who breast feed for a very short period or not at all may belong to population subgroups with an altered risk of breast cancer related to other causes. In such situations it is hard to adjust adequately for potential confounders, and false associations may arise. On the other hand, if a causal association exists, the effect is likely to be weak and thus difficult to detect.

For further evaluation of the relation between lactation and breast cancer, large methodologically sound studies are needed. To minimise bias, prospective studies with detailed information on duration of breast feeding for each child are called for.
Such studies should preferably be conducted in populations with a large proportion of the women practising prolonged breast feeding, in order to detect the possible risk lowering effect of such habits. Future studies should take into account reasons for terminating breast feeding, as well as possible signs from the breasts at the time of weaning. To assess the specificity of a potential association with breast cancer, analyses of the effect of lactation on the risk of other cancers, in particular endometrial cancer, may add valuable information.

The breast cancer screening programme was initiated and organised by the Norwegian Cancer Societv. Gunnar Kvåle has been a Fellow of the Society for work on the project. The authors acknowledge the work of numerous physicians and public health nurses who conducted the interviews, and the coding personnel at the Central Bureau of Statistics and the Cancer Registry of Norway who were responsible for the primary data registration. Dr Einar Pedersen is especially acknowledged for the supervision of the data collection and registration, and we thank Aage Andersen and Geir Egil Eide for assistance in the data processing.

Reprint requests to Dr G Kvåle, Institute of Hygiene and Social Medicine, Haukeland Sykehus, N-5021 Bergen, Norway.

\section{References}

${ }^{1}$ Byers T, Graham S, Rzepka T, et al. Lactation and breast cancer. Evidence for a negative association in premenopausal women. Am J Epidemiol 1985; 121: 664-74.

2 McTiernan A, Thomas DB. Evidence for a protective effect of lactation on risk of breast cancer in young women. Results from a case-control study. Am J Epidemiol 1986; 124: 353-8.

${ }^{3}$ Thomas DB, Epidemiology and related studies of breast cancer etiology. In: Lilienfeld AM, ed. Reviews in cancer epidemiology, Volume 1, New York: Elsevier North Holland, 1980: 153-217.

${ }^{4}$ Kvåle G, Heuch I, Eide GE. A prospective study of reproductive factors and breast cancer. I. Parity. Am J Epidemiol 1987; 126: 831-41.

${ }^{5}$ Kvåle $G$, Heuch I. A prospective study of reproductive factors and breast cancer. II. Age at first and last birth. Am J Epidemiol 1987; 126: 842-50.

${ }^{6}$ Pedersen E. Masseundersøkelser med henblikk pá cancer mammae. Tidsskr Nor Laegeforen 1962; 82: 1042-51.

${ }^{7}$ Lund E. Pilot study for the evaluation of completeness of reporting to the Cancer Registry. In: Incidence of cancer in Norway 1978. Oslo: Cancer Registry of Norway 1981: 11-14.

${ }^{8}$ Heuch I. Manual for use of TRENDPREP. A program preparing data for stratified trend and homogeneity analyses of proportions. Technical report, Department of Mathematics, University of Bergen, 1985, Bergen. 
${ }^{9}$ Thomas DG, Gart JJ. Stratified trend and homogeneity analyses of proportions and life table data. Comput biomed Res 1983; 16: 116-26.

10 Tarone RE. Tests for trend in life table analysis. Biometrika 1975; 62: 679-82.

11 Anderson ID. Breast feeding and breast cancer. $S$ Afr Med $J$ 1975; 49: 479-82.

12 Segi M, Fukushima I, Fujisaku S, et al. An epidemiological study on cancer in Japan. Gann 1957: 48 (Suppl) 1-63.

${ }^{13}$ Ing R, Ho JHC, Petrakis NL. Unilateral breast-feeding and breast cancer. Lancet 1977; ii: 124-7.

14 Wynder EL, Bross IJ, Hirayama T. The epidemiology of breast cancer. Cancer Res 1963; 23: 1503-13.

15 MacMahon B, Lin TM, Lowe CR, et al. Lactation and cancer of the breast. Bull WHO 1970; 42: 185-94.

16 Wynder EL, Escher GC, Mantel N. An epidemiological investigation of cancer of the endometrium. Cancer 1966; 19: 489-520.

${ }^{17}$ Elwood JM, Cole P, Rothman KJ, et al. Epidemiology of endometrial cancer. J Natl Cancer Inst 1977; 59: 1055-60.
${ }^{18}$ Kelsey JL, LiVolsi VA, Holford TR, et al. A case-control study of cancer of the endometrium. Am J Epidemiol 1982; 116: 333-42.

${ }^{19}$ Risch HA, Weiss NS, Lyon JL, et al. Events of reproductive life and the incidence of epithelial ovarian cancer. Am J Epidemiol 1983; 117: 128-39.

20 West RO. Epidemiologic study of malignancies of the ovaries. Cancer 1966; 19: 1001-7.

${ }^{21}$ Wynder EL, Dodo H, Barber HRK. Epidemiology of cancer of the ovary. Cancer 1969; 23: 352-70.

22 Hildreth NG, Kelsey JL, LiVolsi VA, et al. An epidemiologic study of epithelial carcinoma of the ovary. Am J Epidemiol 1981; 114: 398-405.

${ }^{23}$ Heuch I, Kvăle G, Jacobsen BK, et al. Use of alcohol, tobacco and coffee, and risk of pancreatic cancer. $B r J$ Cancer 1983; 48: 637-43.

24 Johansson EDB. The sterile menstrual cycle. The driving force behind pathology in the reproductive organs. Acta Obstet Gynecol Scand (Suppl) 1984; 123: 147-50.

Accepted for publication September 1987 